\title{
Torsional phenomena in 2008 great Wenchuan earthquake*
}

\author{
Fan Yang $^{1}$ Qifeng Luo ${ }^{2, \uparrow}$ and Wei Che ${ }^{3}$ \\ ${ }^{1}$ Research Institute of Structural Engineering and Disaster Reduction, Tongji University, Shanghai 200092, China \\ ${ }^{2}$ Shanghai Institute of Disaster Prevention and Relief, Tongji University, Shanghai 200092, China \\ ${ }^{3}$ School of Engineering and Technology, China University of Geosciences, Beijing 100083, China
}

\begin{abstract}
It is well known that there are some torsional damages in earthquakes. In Taibai park, Jiangyou city, Sichuan province, most of the stone statues, which were placed upon the banisters of one zigzag bridge, exhibited different torsional phenomena in 2008 Wenchuan earthquake. This paper introduces the torsional phenomena of all the statues on the zigzag bridge firstly. Then one eccentricity model is established and the equivalent rotational accelerations are calculated in order to analyze the causes of the torsional damage. In addition, the torsional components are synthesized by using translation accelerations recorded at Jiangyou station in the Wenchuan earthquake. The results show that the equivalent rotational acceleration is larger than the synthesized rotational components, which suggests that the torsional phenomena of the statues on the zigzag bridge might mainly come from its eccentricity. The comparison between the estimated torsional component at Jiangyou and that presented by Trifunac shows that they are in the same order. The research implies that the torsional phenomena in earthquakes are very complicated, and not only caused by torsional motions.
\end{abstract}

Key words: Wenchuan earthquake; Jiangyou; torsional phenomenon; eccentricity; torsional motion CLC number: P315.9 Document code: A

\section{Introduction}

The rotational damage phenomenon appeared in earthquakes is one of the research hotspots in earthquake engineering. In 2009 the journal of Bull Seism Soc Amer published a special issue on rotational seismology and engineering applications. Lee et al (2009) introduced 51 papers in the special issue and considered that rotational seismology is an emerging field for studying all aspects of rotational ground motions induced by earthquakes, explosions, and ambient vibrations. The rotational damage of structure is very complicated. At present, such kind phenomenon can be explained by eccentricity between the center of geometry and that of gravity, and/or rotational components of seismic motions.

Since the rotational components of seismic motions are difficult to be recorded, how to obtain rotational components, directly or indirectly, is one of the main

\footnotetext{
${ }^{*}$ Received 17 November 2009; accepted in revised form 7 January 2010; published 10 February 2010.

•Corresponding author. e-mail: luo@tongji.edu.cn

(c) The Seismological Society of China and Springer-Verlag Berlin Heidelberg 2010
}

problems. So far, four effective methods have been developed. The first is to study seismic rotational component based on focal mechanism and seismic wave propagation theory (Knopoff and Chen, 2009; Kulesh, 2009; Grekova et al, 2009). The second, which is based on elastic wave theory, is to calculate seismic rotational component by three seismic translation component records from a single seismographic station. The method regards asymmetric shearing strain as the main reason for seismic rotational effect. The second method can be further divided as traveling wave method (Newmark, 1969; Penzien and Watable, 1975; Hart et al, 1975; Tso and Hsu, 1978) and frequency domain method (Trifunac, 1982; Lee and Trifunac, 1985; Castellani and Boffi, 1986; Li, 1998). The traveling wave method assumes that seismic torsional component arising from traveling wave. Through the assumption, the method simplifies the displacement expression of seismic translation component and then finds a relation between seismic translation component and seismic torsional component. The frequency domain method maintains that seismic waves including rotational and translation components are composed of many simple harmonic waves with different frequencies. The method, based on elastic semi- 
space theory, is to identify all relations between translation harmonic waves and rotation harmonic waves with the same frequency, and then the relation between seismic translational and rotational components can be given by Fourier inverse transformation. The third method is to calculate the seismic rotational component by seismic translation component records from dense arrays (Niazi, 1982; Oliveira and Bolt, 1989; Huang, 2003; Ghayamghamian and Nouri, 2007). The last method is to develop one new seismic detection systems to directly capture rotational components. Wassermann et al (2009) tested the performance of one commercial rotational motion sensor by comparing its output data which were performed during a demolition blast of a 50 $\mathrm{m}$ high building in the city of Munich (Germany) with the classical array-derived rotational motions. Fichtner and Igel (2009) analyzed sensitivity densities for two quantities, namely, the root mean square (RMS) amplitude and the apparent shear-wave speed, derived from rotational motion measurements.

This paper introduces the torsional phenomena that we observed on a zigzag bridge in Taibai park, Jiangyou city, Sichuan province, after the Wenchuan earthquake. In order to analyze that the torsional damage is caused by eccentricity of the structure or torsional component, one eccentricity model is established and equivalent rotational acceleration is calculated. And then the seismic rotational components are synthesized from the translational accelerations recorded at the Jiangyou seismic station. Finally, the comparison will show the main cause of the torsional damage occurred on the zigzag bridge in Jiangyou.

\section{Torsional phenomena in Jiangyou}

At 14:28 on May 12, 2008 (Beijing time), a great earthquake of $M_{\mathrm{S}} 8.0$ occurred in Wenchuan, Sichuan, China. The focal depth is about $8 \mathrm{~km}$ and the intensity in epicentral area is up to XI. Jiangyou city is located in northwest hilly area of Sichuan, on the southeast of Longmenshan, and lies along the upper reaches of Peihe river. It is about $160 \mathrm{~km}$ far from Wenchuan county and only dozens of kilometers far from the BeichuanYingxiu fault. Jiangyou is one of the harder hit areas in the Wenchuan earthquake. When investigating in Taibai park, Jiangyou city, the authors detected that almost all the stone statues, which are placed upon the banisters of the zigzag bridge, exhibited different torsional displacements (Figures 1-3), with largest torsional displacement being up to $60^{\circ}$. This indicated that the torsional component might exist in the earthquake.

The zigzag bridge is a sight-seeing footbridge with eight bridge decks and reinforced concrete frames, and its master plan is shown in Figure 4. The bridge deck is divided into eight sections. Two end sections of the bridge are $6.5 \mathrm{~m}$ long and $3 \mathrm{~m}$ wide; each middle section is $8.5 \mathrm{~m}$ long and $3 \mathrm{~m}$ wide. The included angle between the two central axes of the adjacent sections is $120^{\circ}$. Totally there are 18 banisters in the joints of adjacent sections, which are $0.6 \mathrm{~m}$ long, $0.4 \mathrm{~m}$ wide and $1.2 \mathrm{~m}$ high; one $0.8 \mathrm{~m}$ high stone statue is placed upon each banister with cubical base being $0.1 \mathrm{~m}$ high. The length and width of each cubical base are a little different from each other. The sizes are shown in the second and the third rows in Table 1. A 0.6-m-high stone lantern is on each status.

Table 1 Translational and torsional displacements for each statue base

\begin{tabular}{|c|c|c|c|c|c|c|}
\hline No. & Base length $/ \mathrm{mm}$ & Base width $/ \mathrm{mm}$ & Direction $/{ }^{\circ}$ & $x / \mathrm{mm}$ & $y / \mathrm{mm}$ & Rotation $z /^{\circ}$ \\
\hline $1(1)$ & 540 & 350 & 35 & +45 & -30 & -5 \\
\hline $2(1)$ & 540 & 350 & 55 & 0 & 0 & 0 \\
\hline 3 (1) & 544 & 274 & 115 & +297 & +17 & -60 \\
\hline $4(1)$ & 540 & 280 & 115 & +60 & -90 & -30 \\
\hline 5 (1) & 530 & 280 & 55 & +40 & -35 & +15 \\
\hline $6(1)$ & 530 & 280 & 55 & 0 & 0 & 0 \\
\hline 7(1) & 514 & 270 & 55 & -10 & +7 & +20 \\
\hline $8(1)$ & 530 & 280 & 45 & 0 & 0 & 0 \\
\hline 9(1) & 534 & 350 & 55 & 0 & +7 & +5 \\
\hline $1^{\prime}(1)$ & 540 & 350 & 35 & 0 & 0 & 0 \\
\hline $2^{\prime}(1)$ & 540 & 350 & 55 & 0 & 0 & 0 \\
\hline $3^{\prime}(3)$ & 544 & 274 & 115 & -29 & +13 & -10 \\
\hline $4^{\prime}(2)$ & 520 & 290 & 115 & +20 & +50 & -5 \\
\hline $5^{\prime}(4)$ & 530 & 290 & 55 & +5 & +5 & -5 \\
\hline $6^{\prime}(4)$ & 530 & 280 & 55 & +60 & +55 & +20 \\
\hline $7^{\prime}(4)$ & 480 & 264 & 55 & +32 & +40 & +15 \\
\hline $8^{\prime}$ (3) & 530 & 270 & 45 & -10 & 0 & -5 \\
\hline $9^{\prime}(1)$ & 534 & 350 & 55 & 0 & 0 & 0 \\
\hline
\end{tabular}




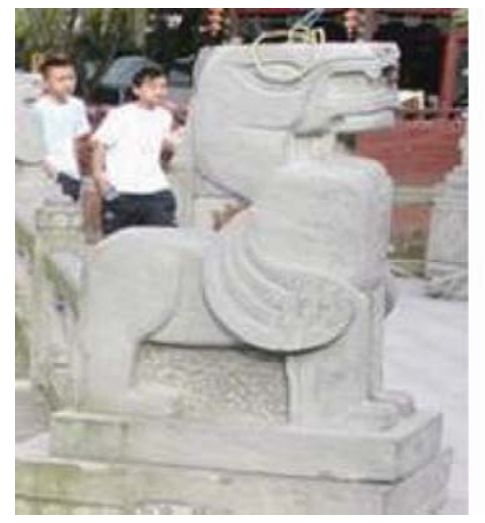

Figure 1 Side view of one stone statue.

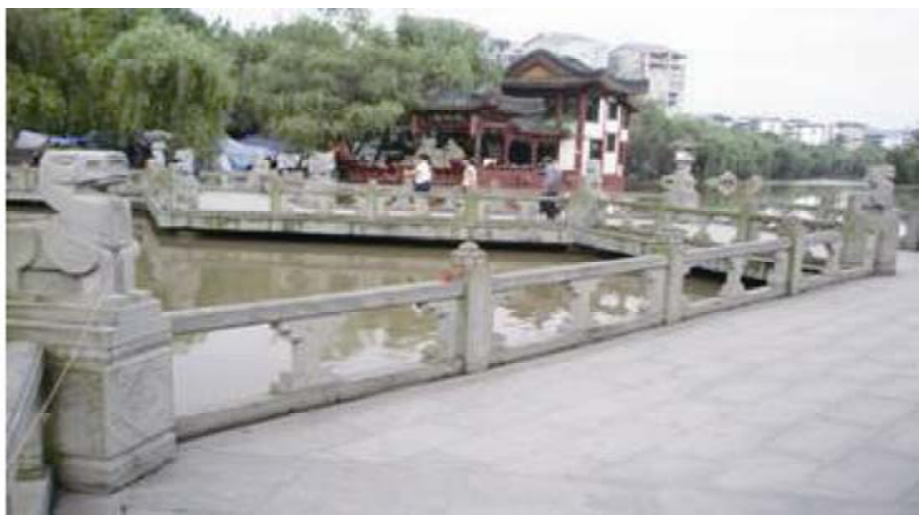

Figure The picture of the zigzagabridge.
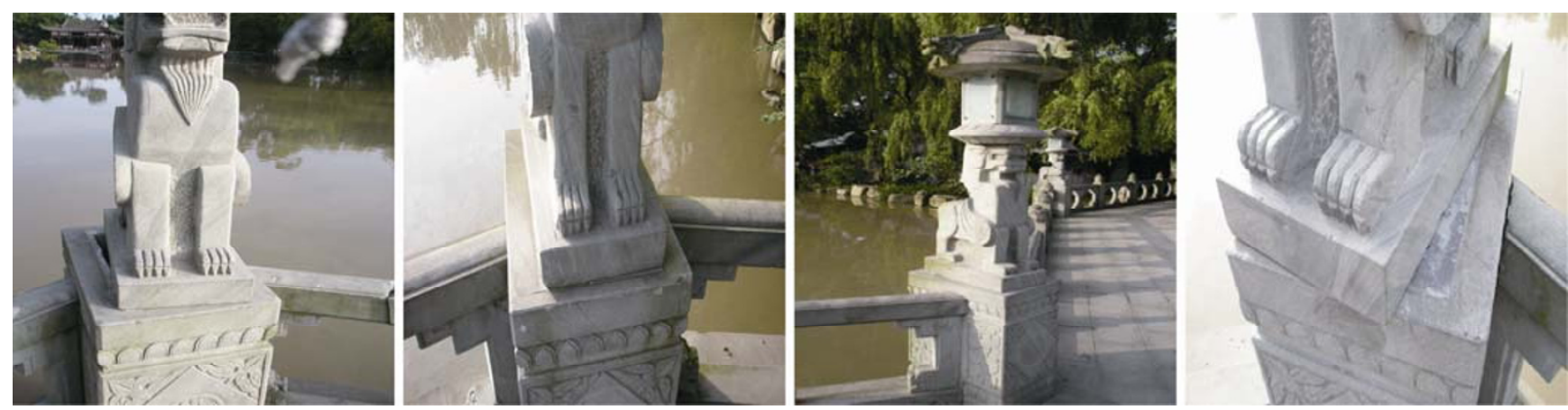

Figure 3 Several torsional phenomena of the statues.

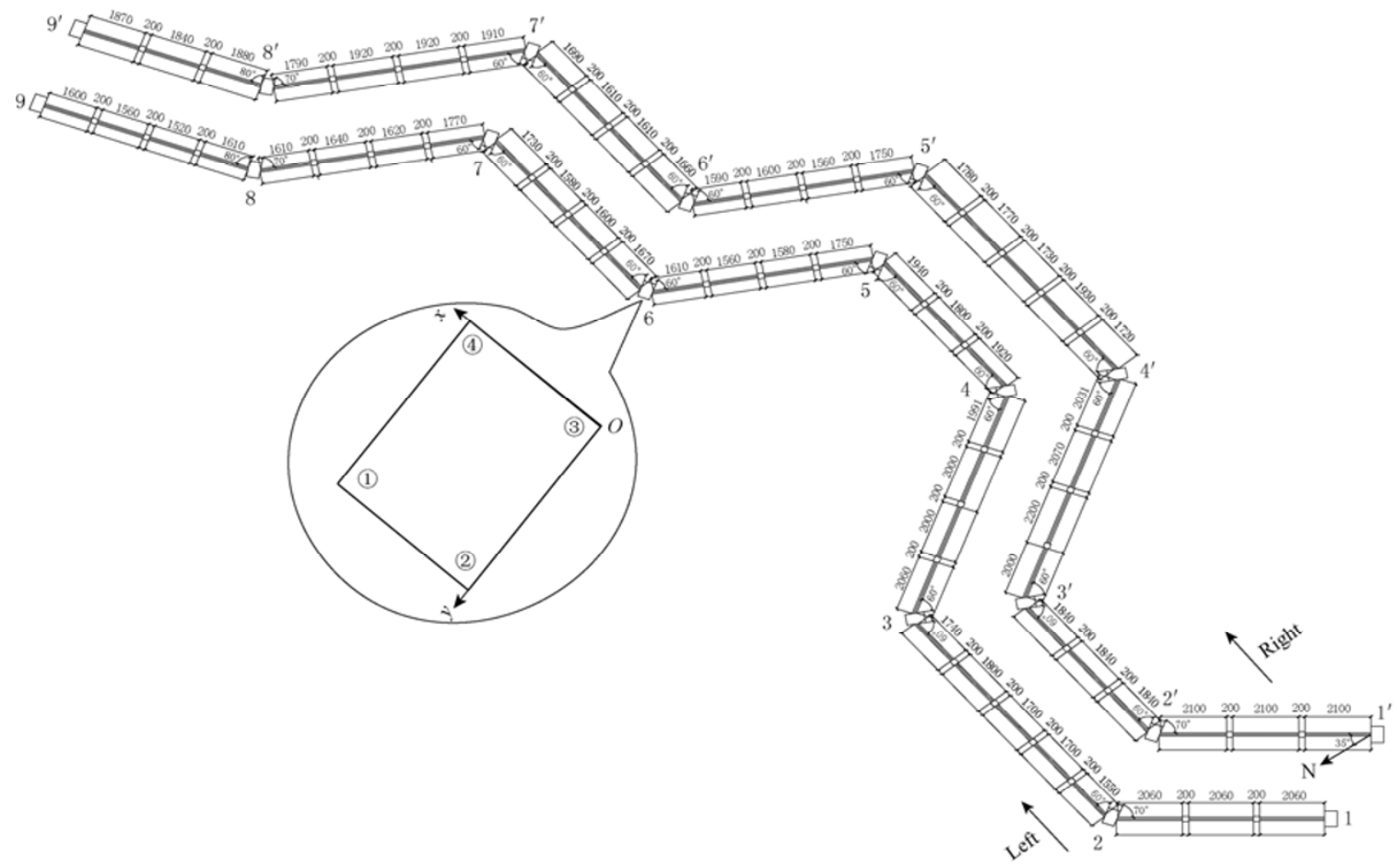

Figure 4 Master plan of a zigzag bridge in Taibai park of Jiangyou. 
For convenience, following the direction of the arrows indicated in Figure 4, the stone statues along the left guardrail are numbered from 1 to 9 and the statues along the right are numbered from $1^{\prime}$ to $9^{\prime}$. The local coordinate system for each statue is different, $x$ - and $y$-axis directions are shown in Figure 4. Its coordinate origin is located at a corner point of the statue base and the four corners are numbered from (1) to (4), which is the same as No. 6 statue in Figure 4. The coordinate origin is assumed to locate at one of the four corners and it is the reference point for measuring. The first column of Table 1 shows all the numbers of the statues and their coordinate origins. Taking the number $6(1)$ in Table 1 as an example, ' 6 ' indicates the No. 6 statue and '(1)' indicates the number of the local coordinate origin. The included angle, from north to $x$-axis in a clockwise direction for each statue, is shown in the fourth row of Table 1.

\section{Equivalent torsional acceleration of stone statue}

As shown in Figure 5, the width and length of the rectangle statue base is separately $b$ and $l$, the heights of the head part and tail part of the statue are $h$ and $h / 2$, respectively; the length of the head part is $2 l / 3$ and that of the tail part is $l / 3$. For installing the wire for the lantern located upon the statue, there is a cylinder hole in the statue with radius of $0.1 l$. The height of the head part is twice as tall as that of the tail; consequently, planar density of the head area of statue is $2 \rho$, where $\rho$ is that of the tail area. There is a stone lantern on the top of the statue head (see Figure 3c), which is very heavy. Considering the change in planar density due to the fact that some of the stone lantern fell down in the earthquake, this paper will discuss two cases: with a stone lantern or without it. When there is stone lantern, planar density of

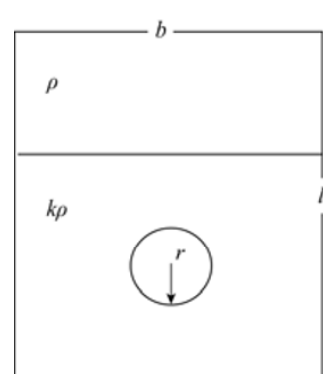

(a)

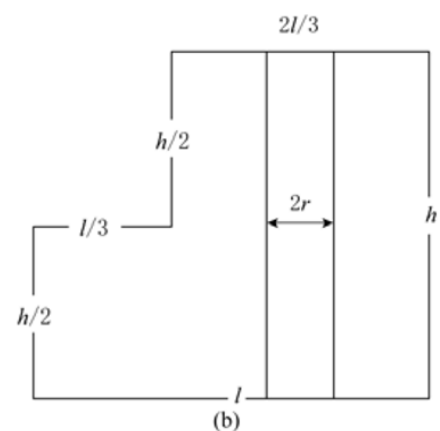

(b)
Figure 5 Calculation model of the stone statue. (a) Plan of the statue base; (b) Calculation model of the stone statue. the head area of statue is $3 \rho$. Otherwise, it is $2 \rho$. The eccentricity exits on the length direction, but no on the width direction. If the input acceleration along the width direction is $a$, the inertia torque, which results from eccentricity, is

$$
\begin{gathered}
L=\left[\int_{l / 6}^{l / 2} \rho b \tau \mathrm{d} \tau+\int_{-l / 2}^{l / 6} k \rho b \tau \mathrm{d} \tau+k \rho \pi r^{2}\left(\frac{l}{6}\right)\right] a= \\
\left(\frac{1-k}{9} b l^{2}+\frac{k}{6} \pi r^{2} l\right) \rho a,
\end{gathered}
$$

where $\tau$ is an variable of integration. The moment of inertia $I$ of the statue is

$$
\begin{gathered}
I=\int_{l / 6}^{l / 2} \rho b r^{2} \mathrm{~d} r+\int_{-l / 2}^{l / 6} k \rho b r^{2} \mathrm{~d} r- \\
{\left[\frac{k \rho \pi r^{4}}{2}+k \rho \pi r^{2}\left(\frac{l}{6}\right)^{2}\right]=} \\
{\left[\left(\frac{13}{324}+\frac{7 k}{162}\right) b l^{3}-\frac{k \pi r^{4}}{2}-\frac{k \pi r^{2} l^{2}}{36}\right] \rho .}
\end{gathered}
$$

According to the inertia torque equivalence principle, equivalent torsional acceleration is

$$
\begin{gathered}
\ddot{\varphi}=\frac{L}{I}=\frac{\left(\frac{1-k}{9} b l^{2}+\frac{k}{6} \pi r^{2} l\right) \rho a}{\left[\left(\frac{13}{324}+\frac{7 k}{162}\right) b l^{3}-\frac{k \pi r^{4}}{2}-\frac{k \pi r^{2} l^{2}}{36}\right] \rho}= \\
\frac{\left(\frac{1-k}{9} b l^{2}+\frac{k}{6} \pi r^{2} l\right)}{\left(\frac{13}{324}+\frac{7 k}{162}\right) b l^{3}-\frac{k \pi r^{4}}{2}-\frac{k \pi r^{2} l^{2}}{36}}(u \sin \theta+v \cos \theta) .
\end{gathered}
$$

where, $u$ is the input acceleration in east-west direction, $v$ the input acceleration in north-south direction and $\theta$ an included angle between width direction of the statue and the north-south direction. By equation (3) the equivalent torsional acceleration $\ddot{\varphi}$ in case 1 (there is a stone lantern on the top of the statue head) and case 2 (there is no stone lantern) can be calculated. Figures 6 and 7 show relevant equivalent torsional accelerations for the statues in the right row (see Figure 4).

Figures 6 and 7 show there is little difference in amplitude and in waveform of the equivalent torsional acceleration for different stone statue in the same case. The maximum equivalent torsional acceleration is about $10 \mathrm{rad} / \mathrm{s}^{2}$ in the case 1 and that in the case 2 is smaller, which is about $6 \mathrm{rad} / \mathrm{s}^{2}$. 

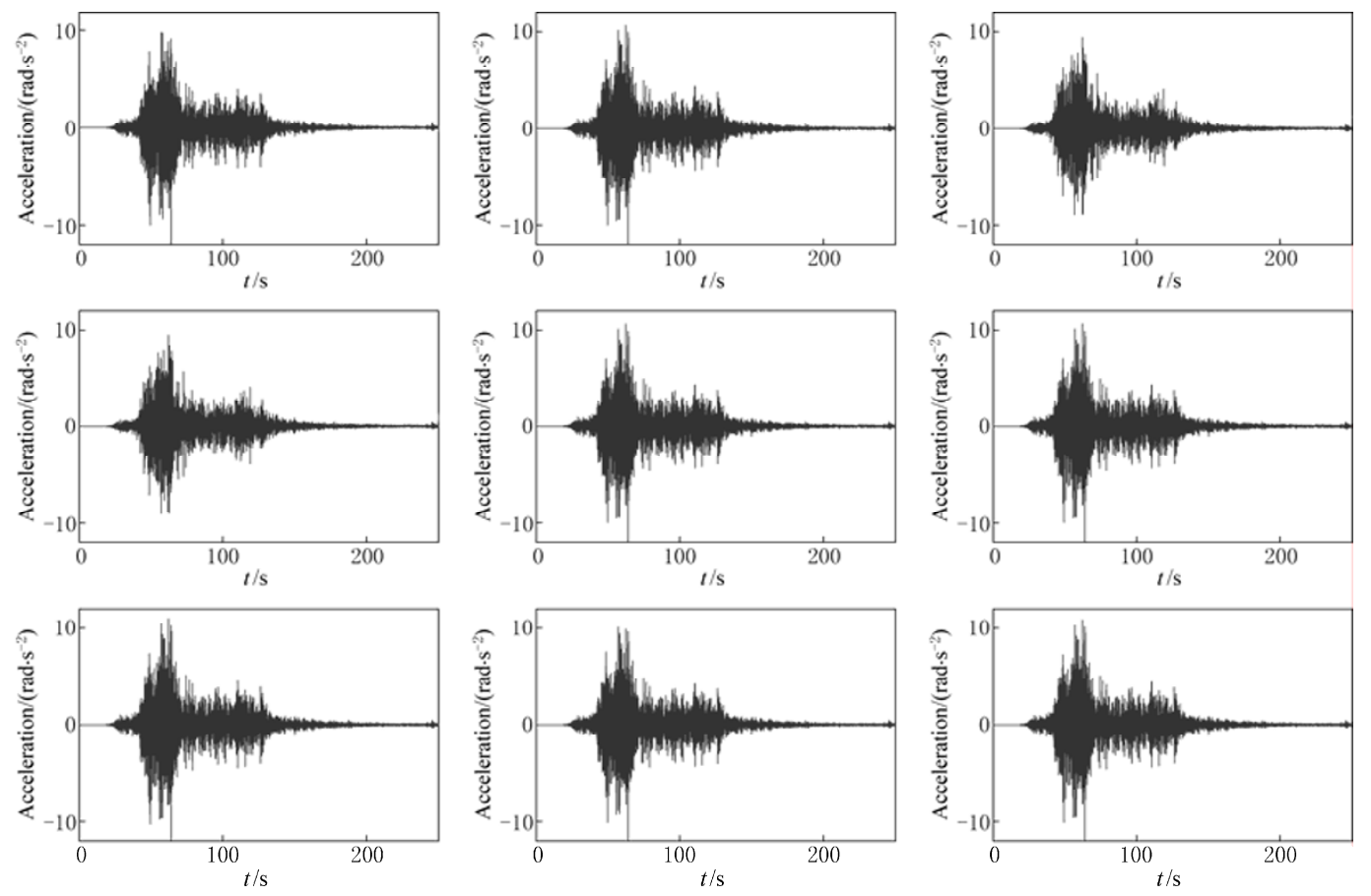

Figure 6 Equivalent torsional accelerations of nine statues in the case 1.
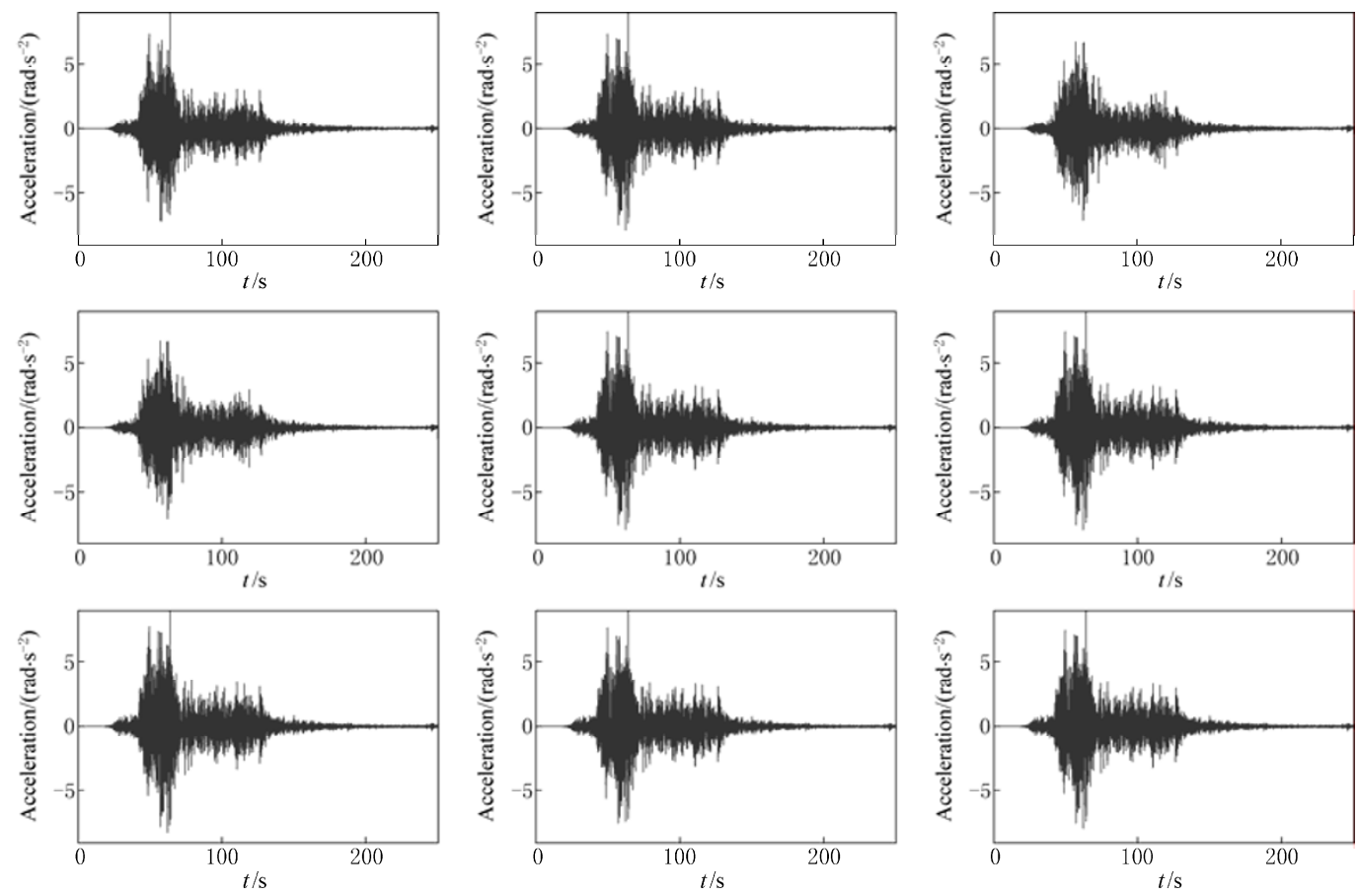

Figure 7 Equivalent torsional accelerations of nine statues in the case 2.

4 Rotational components at Jiangyou station in Wenchuan earthquake

Che and Luo (2010) synthesized the rotational ground motion using one station translational accelera- tions of the Jiji (Chi-Chi) earthquake. Here, we apply the same method to estimate the rotational component at Jiangyou station in Wenchuan earthquake. Three translational accelerations were recorded at Jiangyou station with the maximum acceleration of $5.11 \mathrm{~m} / \mathrm{s}^{2}$ in the EW 
direction (Figure 8). It is assumed that the seismic ground motion is generated by plane harmonic waves arriving at the site. The direction of propagation of the seismic wave lies in the vertical $(x, z)$ plane. The coordinate system is shown in Figure 9. It is supposed that the seismic waves propagate in a homogeneous isotropic elastic half-space or a layered elastic half-space, and the near-field seismic motion is produced by body waves. The relation between the Fourier spectrum of the rotational motion and that of the translational motion can be written as (Wang, 1995; Sun and Chen, 1998)

$$
\ddot{\varphi}_{g z}(\omega)=\mathrm{i} \omega \frac{\ddot{v}(\omega)}{2 c(f)}
$$

where $\ddot{\varphi}_{g z}(\omega)$ is the Fourier spectrum of the torsional components, $\mathrm{i}=\sqrt{-1}, c(f)$ denotes the apparent velocity
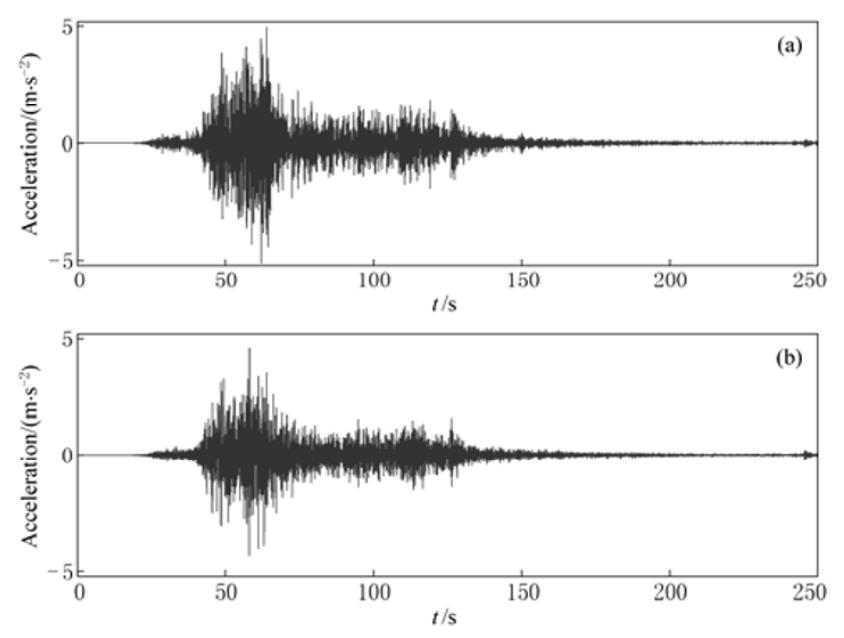

Figure 8 Acceleration recorded at Jiangyou station. (a) E-W direction; (b) N-S direction.

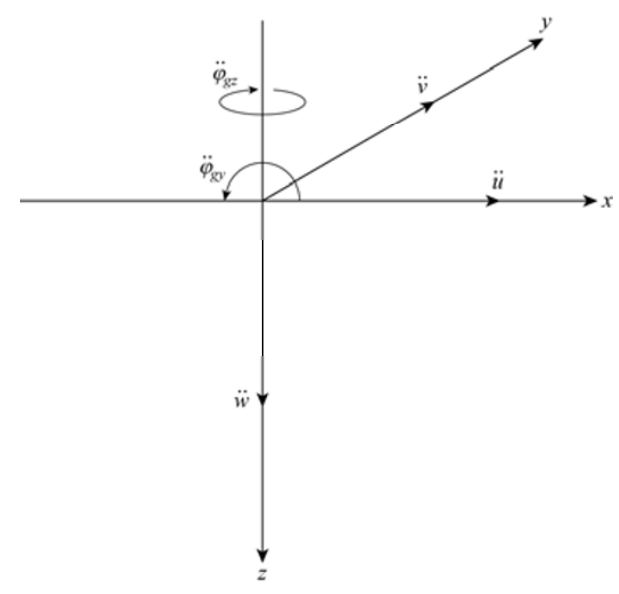

Figure 9 The coordinate system. of the body waves; and $\ddot{v}(\omega)$ is the Fourier spectrum of out-of-plane components, respectively. Through Fourier inverse transform, the time history of the torsional component can be obtained. The method considers the dispersion of seismic waves caused by the inhomogeneous mediums of propagation.

The apparent velocity $c(f)$ of the body waves is estimated by

$$
\begin{gathered}
\bar{c}(f)=5.426+1.646 \lg f-0.814(\lg f)^{2}, \\
c(f)=\bar{c}(f)(1+0.2 \zeta),
\end{gathered}
$$

where $f$ is frequency in $\mathrm{Hz}$, and $\zeta$ is a random number in $(-1,1)$.

The torsional acceleration is synthesized in terms of the translation records at Jiangyou station in Wenchuan earthquake (Figure 10). The maximum of the torsional acceleration is about $0.03 \mathrm{rad} / \mathrm{s}^{2}$. Comparing with the maximum equivalent torsional acceleration calculated in the section 3 , the synthesized torsional component is very small, but it is consistent with that presented by Trifunac (2009), in which the rotations rang from $10^{-6} \mathrm{rad}$ to $10^{-3}$ $\mathrm{rad}$ and accelerations from $10^{-4} \mathrm{rad} / \mathrm{s}^{2}$ to $10^{-1} \mathrm{rad} / \mathrm{s}^{2}$.

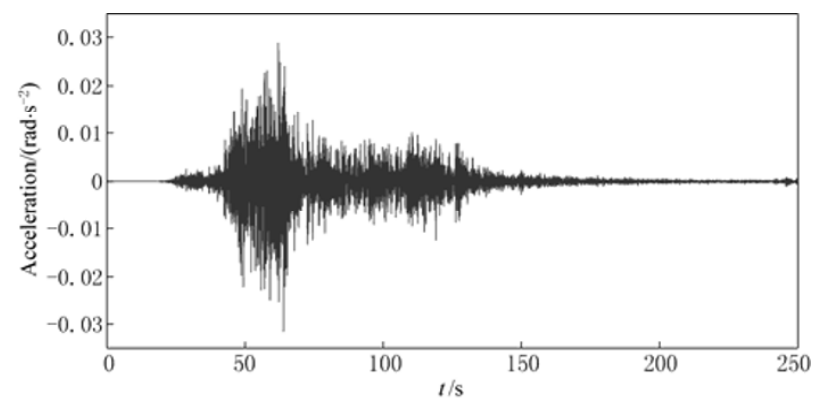

Figure 10 Synthesized torsional acceleration component at Jiangyou station.

\section{Discussion and conclusions}

This paper firstly introduced the torsional phenomena appeared on the zigzag bridge in Taibai park in the 2008 great Wenchuan earthquake, which the authors found when making field investigation in Jiangyou, Sichuan province. There are two possible reasons to explain such kind of phenomenon, that is, it is caused by the eccentricity of the statues and the torsional component of ground motions.

For finding out the main reason to explain the torsional phenomena, considering the eccentricity of the stone statues, we calculated the equivalent accelerations of nine stone statues in two cases, that there is stone lan- 
tern locked upon the statue (case 1) or not (case 2). And then the torsional component is synthesized using the translational accelerations recorded at Jiangyou station. The calculated peak equivalent torsional acceleration is about $10 \mathrm{rad} / \mathrm{s}^{2}$ in the case 1 and $6 \mathrm{rad} / \mathrm{s}^{2}$ in the case 2 , but the synthesized peak torsional acceleration is about $0.03 \mathrm{rad} / \mathrm{s}^{2}$. It is obvious that they are not in the same order of magnitude, from which it can be concluded that the torsional phenomena of the statues on the zigzag bridge is mainly affected by its eccentricity. Therefore, the anti-torque moment caused by structural eccentricity should be considered in seismic design.

The rotations and accelerations presented by Trifunac (2009) range separately from $10^{-6} \mathrm{rad}$ to $10^{-3} \mathrm{rad}$ and from $10^{-4} \mathrm{rad} / \mathrm{s}^{2}$ to $10^{-1} \mathrm{rad} / \mathrm{s}^{2}$. This paper indicates that the estimated torsional component at Jiangyou in Wenchuan earthquake and the results present by Trifunac are in the same order magnitude. And also the research implies that the torsional phenomena in earthquakes are very complicated, which were not only caused by the torsional motions. We should continue to collect more information and forward the research on rotational phenomena and rotational motions.

Acknowledgements This study is supported by the National Natural Science Foundation of China (No. 50578125).

\section{References}

Castellani A and Boffi G (1986). Rotational components of the surface ground motion during an earthquake. Earthq Eng Struct Dynam 14(7): 751-767

Che W and Luo Q (2010). Time-frequency response spectrum of rotational ground motion and its application. Earthquake Science 23(1): 71-77.

Fichtner A and Igel H (2009). Sensitivity densities for rotational ground-motion measurements. Bull Seism Soc Amer 99(2B): 1302-1 314.

Ghayamghamian M R and Nouri G R (2007). On the characteristics of ground motion rotational components using Chiba dense array data. Earthq Eng Struct Dynam 36: 1407-1 429.
Grekova E F, Kulesh M A and Herman G C (2009). Waves in linear elastic media with microrotations. Part 2: Isotropic reduced crosserat model. Bull Seism Soc Amer 99(2B): 1 423-1 428.

Hart G C, Lew M and DiJulio R M (1975). Torsional response of high-rise buildings. J Struct Div 101(2): 397-416.

Huang B S (2003). Ground rotational motions of the 1999 Chi-Chi Taiwan earthquake as inferred from dense array observations. Geophys Res Lett 30(6): 1307-1310.

Knopoff L and Chen Y T (2009). Single-couple component of far-field radiation from dynamical fractures. Bull Seism Soc Amer 99(2B): 1 091-1 102.

Kulesh M (2009). Waves in linear elastic media with microrotations. Part 1: Isotropic full crosserat model. Bull Seism Soc Amer 99(2B): 1 416-1 422.

Lee V W and Trifunac M D (1985). Torsional accelerograms. Int J Soil Dynam Earthq Eng 4(3): 132-139.

Lee W H K, Celebi M, Todorovska M I and Igel H (2009). Introduction to the special issue on rotational seismology and engineering applications. Bull Seism Soc Amer 99(2B): 945-957.

Li H N (1998). Theoretical Analysis and Design of Structures to Multiple Earthquake Excitations. Science Press, Beijing, 22-31 (in Chinese).

Newmark N M (1969). Torsional in symmetrical buildings. Proceeding of the 4th World Conference on Earthquake Engineering. Santiago, Chile, Jan. 13-18, 1969, 6: A3.19-A3.32.

Niazi M (1982). Inferred displacements, velocities and rotations of a long rigid foundation located at El Centro differential array site during the 1979, Imperial Valley, California earthquake. Earthq Eng Struct Dynam 14(4): 531-542.

Oliveira C S and Bolt B A (1989). Rotational components of surface strong ground motion. Earthq Eng Struct Dynam 18(4): 517-526.

Penzien J and Watable W (1975). Characteristics of three-dimensional earthquake ground motions. Earthq Eng Struct Dynam 13(4): 365-373.

Sun S J and Chen G X (1998). Synthesis method for estimation of rotation components of ground motion. Journal of Seismology (1): 19-24 (in Chinese with English abstract).

Trifunac M D (1982). A note on rotational components of earthquake motions on ground surface for incident body waves. Soil Dynam Earthq Eng 1(1): $11-19$.

Trifunac M D (2009). Review: Rotation in structural response. Bull Seism Soc Amer 99(2B): 968-979.

Tso W K and Hsu T I (1978). Torsional spectrum for earthquake motion. Earthq Eng Struct Dynam 6(4): 375-382.

Wang J J (1995). The effects of torsional ground motion on thin cylindric shell structures. Aata Seismologica Sinica 8(2): 265-270.

Wassermann J, Lehndorfer S, Igel H and Schrelbeer U (2009). Performance test of a commercial rotational motions sensor. Bull Seism Soc Amer 99(2B): 1449-1 456. 